\title{
NEUTRAL UPPER ATMOSPHERES OF THE OUTER PLANETS
}

\author{
S. K. Atreya \\ Department of Atmospheric and Oceanic Science, The University of Michigan, \\ Ann Arbor, MI 48109-2143, U.S.A.
}

\begin{abstract}
Several recent papers have reviewed the upper atmospheres and ionospheres of Jupiter and Saturn in the post Voyager era (see, e.g., /1/ and references therein). Therefore, this paper will review only the most salient characteristics, as far as Jupiter and Saturn are concerned. The emphasis here, however, is placed on the Uranus upper atmosphere that was probed in January, 1986, by Voyager 2 spacecraft. In particular comparative aspects of atmospheric composition, thermal structure, photochemistry and the vertical mixing are discussed.
\end{abstract}

For all practical purposes, the bulk compositions of the atmospheres of Jupiter and Saturn are reflective of the solar ratios of the elements. The mixing ratios of atmospheric constituents on Jupiter are shown in Figure 1. Due to the relatively low tropospheric temperatures on Jupiter, $\mathrm{H}_{2} \mathrm{O}, \mathrm{H}_{2} \mathrm{~S}$ and $\mathrm{NH}_{3}$ would condense at the 2-5, 1.5-2.5 and 0.7-0.4 bar pressure levels respectively. Similar condensation is expected for Saturn. On Uranus, condensation of $\mathrm{CH}_{4}$ at $\sim 1300 \mathrm{mb}$, and formation of an aqueous-ammonia solution cloud and an $\mathrm{H}_{2} \mathrm{~S}$-ice cloud are also expected. Despite the recent Voyager flyby of Uranus, the inventory of detected species on this planet remains unaltered. Unlike Jupiter and Saturn, there are only a handful of constituents that have been detected on Uranus, as is evident from Table 1. Noteworthy in this table are $\mathrm{NH}_{3}, \mathrm{CH}_{4}$ and $\mathrm{H}$. The depletion of $\mathrm{NH}_{3}$ relative to the value corresponding to the solar $\mathrm{N} / \mathrm{H}$ ratio $\left(8.7 \times 10^{-5}\right)$ is most likely due to the removal of 75 to $95 \%$ of $\mathrm{NH}_{3}$ in an aqueous-ammonia solution cloud $/ 3 /$. This cloud is expected to form deep in the troposphere (at $\sim 400$ bars) and extend all the way to the 100-bar level $/ 3 /$. Consequently, atmospheric depletion of $\mathrm{NH}_{3}$ does not necessarily imply a depletion in N/H in the bulk composition of Uranus. This may not be true of $\mathrm{CH}_{4}$, however, which does indicate a significant enhancement over the solar $\mathrm{C} / \mathrm{H}$. It is also interesting to note that the intensity of Lyman-alpha emission does not follow the usual pattern of resonance scattering of the solar Lyman-alpha photons by the atmospheric hydrogen atoms. This mechanism produces approximately $200 \mathrm{R}$ of Lya 14/, whereas the observed intensity is on the order of $1400 \mathrm{R} / 4,5 /$. A portion of the observed intensity ( $\sim 300 \mathrm{R})$ is expected to be due to the backscattering of the interplanetary/interstellar hydrogen Lyman-alpha. The remaining is attributed to 'electroglow'. The characteristics of the observed emission are such that a new term (electroglow) was coined by the Voyager/UVS group /5/ to describe this phenomena. The emission is present over the entire sunlit hemisphere of the planet and is seen in $\mathrm{H}$ Lyman-alpha as well as $\mathrm{H}_{2}$ Lyman and Werner bands. The excitation of the latter requires electrons with approximately $3 \mathrm{eV}$ Maxwellian energy distribution. Electroglow differs from conventional airglow or dayglow which is excited by the solar EUV (photons or photoelectrons). It also differs from conventional aurora, although both require charged particles. Unlike the aurora, however, electroglow results from the precipitation of 'soft' energy electrons, and it is not confined to the 'auroral' latitudes only. The source of this soft electron precipitation on the dayside only remains a mystery.

The power input implied from the electroglow is on the order of $2 \times 10^{11}$ Watts which is roughly equivalent to power input in the auroral regions of Uranus or Saturn. This has interesting implications for Uranus, as the electroglow power input is about 2 orders of magnitude greater than the absorbed solar energy. The most dramatic consequence of this is the existence of a corona around Uranus. Since the planetary radius is relatively small (compared to Jupiter and Saturn), the high exospheric temperature resulting from electroglow energy forms an extensive corona of hydrogen. Note also that the escape energy from Uranus $(2 \mathrm{eV})$ is overcome by nearly $1 / 2$ of the $\mathrm{H}$-atoms created on dissociation of $\mathrm{H}_{2}$ by the electroglow electrons. The 'exobase' or 'critical level' is reached at a distance where the mean free path $(\lambda)$ is equal to the scale height $(H)$, i.e.,

$$
\lambda_{c}=\left(n_{c} Q_{c}\right)^{-1}=H_{c}
$$

where $\mathbf{n}$ and $\mathrm{Q}$ are respectively atmospheric density and collisional cross section; subscript $\mathrm{c}$ refers to the critical level. 


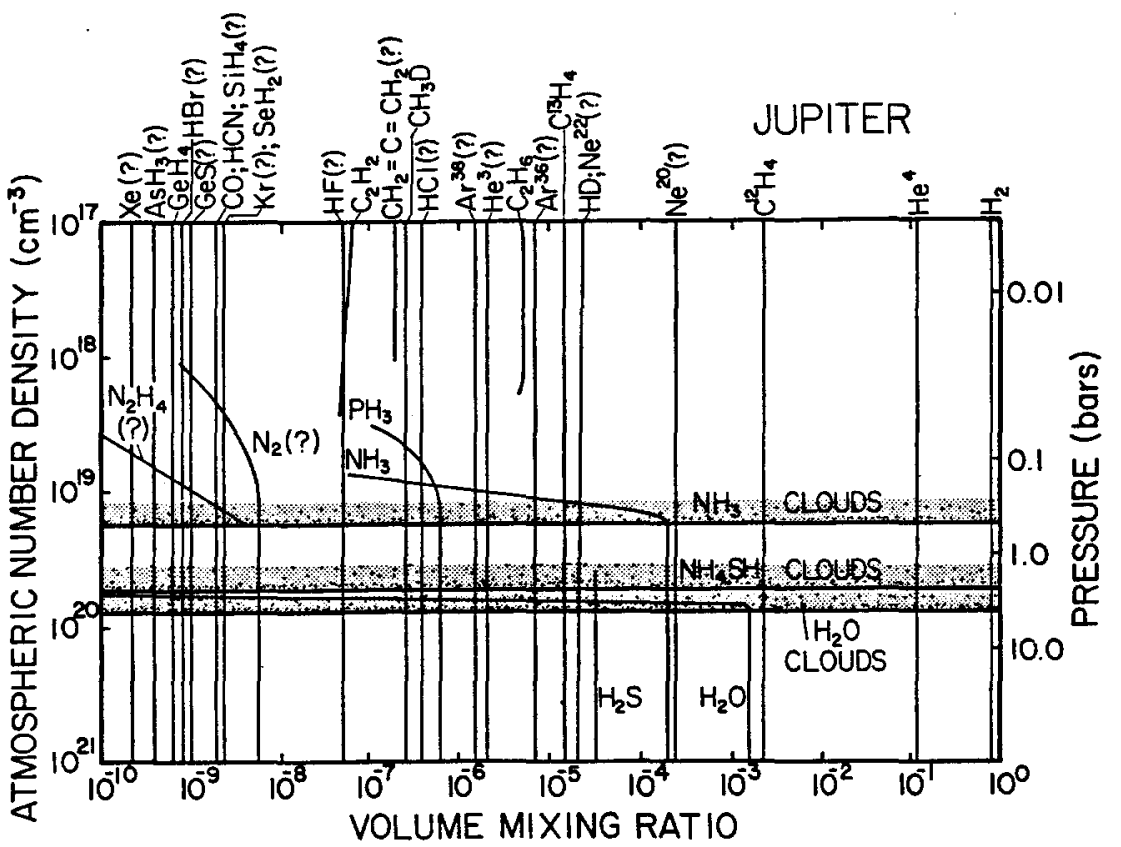

Fig. 1. A cartoon showing volume mixing ratios of the principal constituents in the atmosphere of Jupiter. Atmospheric density (left ordinate) corresponds to the pressure on the right ordinate. Constituents marked '?' are expected to be present but not yet detected. Locations of the main clouds $-\mathrm{H}_{2} \mathrm{O}, \mathrm{NH}_{4} \mathrm{SH}$ and $\mathrm{NH}_{3}$ are shown by the stippled areas. Only the $\mathrm{NH}_{3}$ cloud has so far been inferred from observations (After $/ 2 /$ ).

The critical level at Uranus lies at a radius of $1.25 \mathrm{R}_{\mathrm{u}}\left(1 \mathrm{R}_{\mathrm{u}}=25,550 \mathrm{~km}\right.$ is the radius at the 1-bar level) where the density is $6 \times 10^{6} \mathrm{~cm}^{-3}$. The upper atmospheric density has been monitored by Voyager/UVS using the solar and stellar occultations. Examples of the lightcurves obtained at Uranus 'entry' occultation are shown in Figure 2. Continuum absorption in $\mathrm{H}_{2}$ (top panel in Figure 2) at very high altitudes illustrates the existence of abovementioned corona. A much weaker absorption in the $\mathrm{H}_{2}$ Lyman and Werner bands (1070-1115 $\AA$ panel in Figure 2) yields $\mathrm{H}_{2}$ density and atmospheric temperature to deeper levels. The absorption in the $1255-1355 \AA$ region is primarily due to the hydrocarbons and it occurs at and below the homopause level. The upper atmospheric density and thermal structure resulting from the Voyager observations of Uranus are shown in Figure 3 . The exospheric temperature reaches $750 \pm 100 \mathrm{~K}$. It is independent of latitude, as would be expected from the nature of energy deposition from electroglow electrons. In fact, the energy from these electrons $\left(0.075 \mathrm{erg} \mathrm{cm}^{-2} \mathrm{~s}^{-1}\right)$ combined with a small contribution from the auroral energy $\left(0.025 \mathrm{erg} \mathrm{cm}^{-2} \mathrm{~s}^{-1}\right)$ is sufficient to explain the $750 \mathrm{~K}$ exospheric temperature at Uranus. (In arriving at the auroral energy flux it is assumed that the auroral power is uniformly spread over the entire planet by thermospheric winds.) It is important to recognize that electroglow has now been deduced to be present also on Saturn and Jupiter, although to a lesser degree than on Uranus. High exospheric temperatures have been measured also on Jupiter and Saturn. They can, however, be explained almost entirely by a global distribution of the auroral power. For the sake of completeness, the atmospheric density and thermal structure models of Jupiter and Saturn are shown in Figures 4 and 5. As on Uranus, the upper atmospheric information is deduced from the solar and stellar occultation experiments, whereas stratospheric and tropospheric data come from the radio and IR experiments done on Voyager.

The abovementioned occultation experiments yield information on another parameter of crucial importance in planetary aeronomy - the eddy diffusion coefficient, $\mathrm{K}$. In general, by monitoring the height distributions of a heavy trace constituent one can determine the level of the homopause. Once this level is known, the eddy diffusion coefficient there is simply equal to the molecular diffusion coefficient. The latter can be determined from gas kinetic considerations and the relevant experimental data. In the atmospheres of the outer planets $\mathrm{CH}_{4}$ serves as an appropriate trace gas for determining $\mathrm{K}$. The situation, however, is less than straightforward, as $\mathrm{CH}_{4}$ undergoes photolysis. As a result, $\mathrm{CH}_{4}$ concentration could drop well below the homopause giving an impression of the homopause level. Thus, it is imperative that photochemical calculations be taken into consideration when determining $\mathrm{K}$. The basic photochemical scheme of $\mathrm{CH}_{4}$ on the outer planets is shown in Figure 6 . The photolysis of methane occurs primarily below $1600 \AA$ and it results in the formation of radicals ${ }^{3} \mathrm{CH}_{2},{ }^{1} \mathrm{CH}_{2}$ and $\mathrm{CH}$. After a series of reactions stable hydrocarbon products, $\mathrm{C}_{2} \mathrm{H}_{4}, \mathrm{C}_{2} \mathrm{H}_{6}$ and $\mathrm{C}_{2} \mathrm{H}_{2}$ are formed. The photochemical results depend on chemical reaction rates, atmospheric thermal structure and the diffusion coefficients. The first two items are relatively well known, so that the chemical models can be parameterized in terms of the eddy diffusion coefficient. The chemical model that best reproduces the observed occultation lightcurves for the hydrocarbons 
Table 1. Composition of Uranus and Neptune Atmospheres

\begin{tabular}{|c|c|c|}
\hline Constituent & Uranus & Neptune \\
\hline $\mathrm{H}_{2}$ & $500-700 \mathrm{~km}-\mathrm{am}$ & $300-600 \mathrm{~km}-\mathrm{am}$ \\
\hline $\mathrm{He}$ & $\mathrm{He} / \mathrm{H}_{2}=0.18 \pm 0.07$ & \\
\hline HD & $1.8 \times 10^{-5}<\mathrm{D} / \mathrm{H}<4 \times 10^{-4}$ & $?$ \\
\hline $\mathrm{NH}_{3}$ & $\begin{array}{l}\mathrm{N} / \mathrm{H}<10^{-6} \text { in } \\
150-200 \mathrm{~K} \text { range }\end{array}$ & less than solar \\
\hline $\mathrm{CH}_{4}$ & $\sim 20 \times$ solar & up to $60 \times$ solar \\
\hline $\mathrm{C}_{2} \mathrm{H}_{6}$ & $\begin{array}{l}<3 \times 10^{-8} \text { in the } \\
\text { stratosphere }\end{array}$ & $\begin{array}{l}3 \times 10^{-6} \text { in the } \\
\text { stratosphere }\end{array}$ \\
\hline $\begin{array}{l}\mathrm{C}_{2} \mathrm{H}_{2} \\
(\text { IUE, }>1600 \AA) \\
(\text { Voyager, } 1400-1600 \AA)\end{array}$ & $\begin{array}{l}(6.8 \pm 3.4) \times 10^{16} \mathrm{~cm}^{-2} \\
2 \times 10^{16} \mathrm{~cm}^{-2}\end{array}$ & \\
\hline $\begin{array}{l}\text { H(IUE, } 1216 \AA \text { ) } \\
\text { (Voyager, } 1216 \AA \text { ) }\end{array}$ & $\begin{array}{l}\text { Ly } \alpha=1.4 \mathrm{kR} \\
\mathrm{Ly} \alpha=1.5 \mathrm{kR}\end{array}$ & $<300 \mathrm{R}$ \\
\hline
\end{tabular}

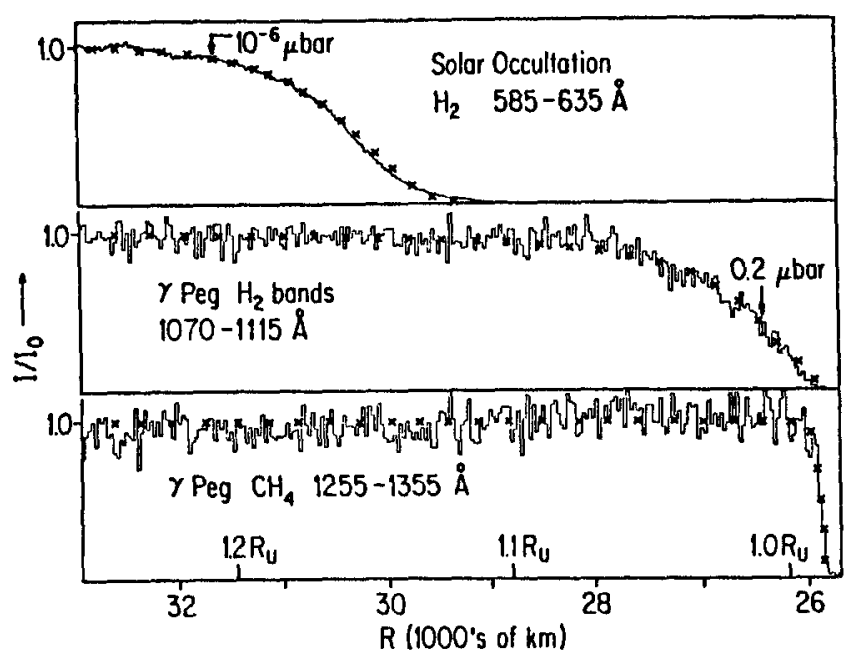

Fig. 2. UV solar and stellar occultation light curves recorded by Voyager 2 at Uranus (After /5/). The $\gamma$ Pegasi observations are for high latitudes $\left(\sim 60^{\circ}\right)$, whereas the solar occultations correspond to equatorial regions $\left(\sim 4^{\circ}\right)$.

yields the value of eddy diffusion coefficient. In addition to this method, actual hydrocarbon profiles resulting from the occultation experiments are also compared with those from the photochemical models. A synopsis of the resulting eddy diffusion coefficients is given in Table 2 . Note that amongst the major planets, Uranus seems to have the lowest value of eddy diffusion coefficient. This implies a relatively sluggish vertical mixing that is perhaps related to the fact that Uranus, unlike Jupiter, Saturn and Neptune, does not have any substantial internal heat source. 


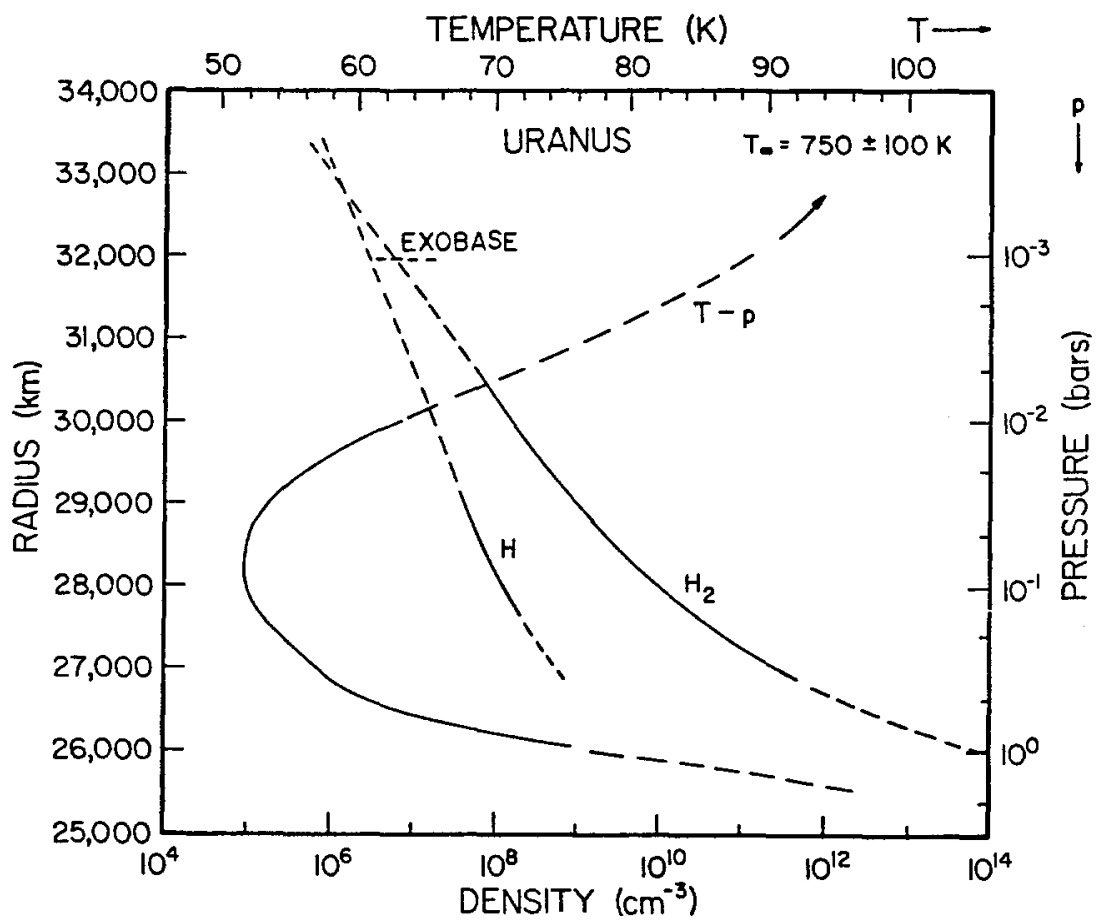

Fig. 3. Model of the atmosphere of Uranus.

Thermal structure is a composite of Voyager UV occultation results (upper atmosphere) and the IR and Radio observations (for $\mathrm{P}>1 \mathrm{mb}$ ). Note the presence of an extensive corona of hydrogen. Broken lines represent interor extra-polations to the available data (From $/ 2 /$, adapted from data of various Voyager 2 experiments).

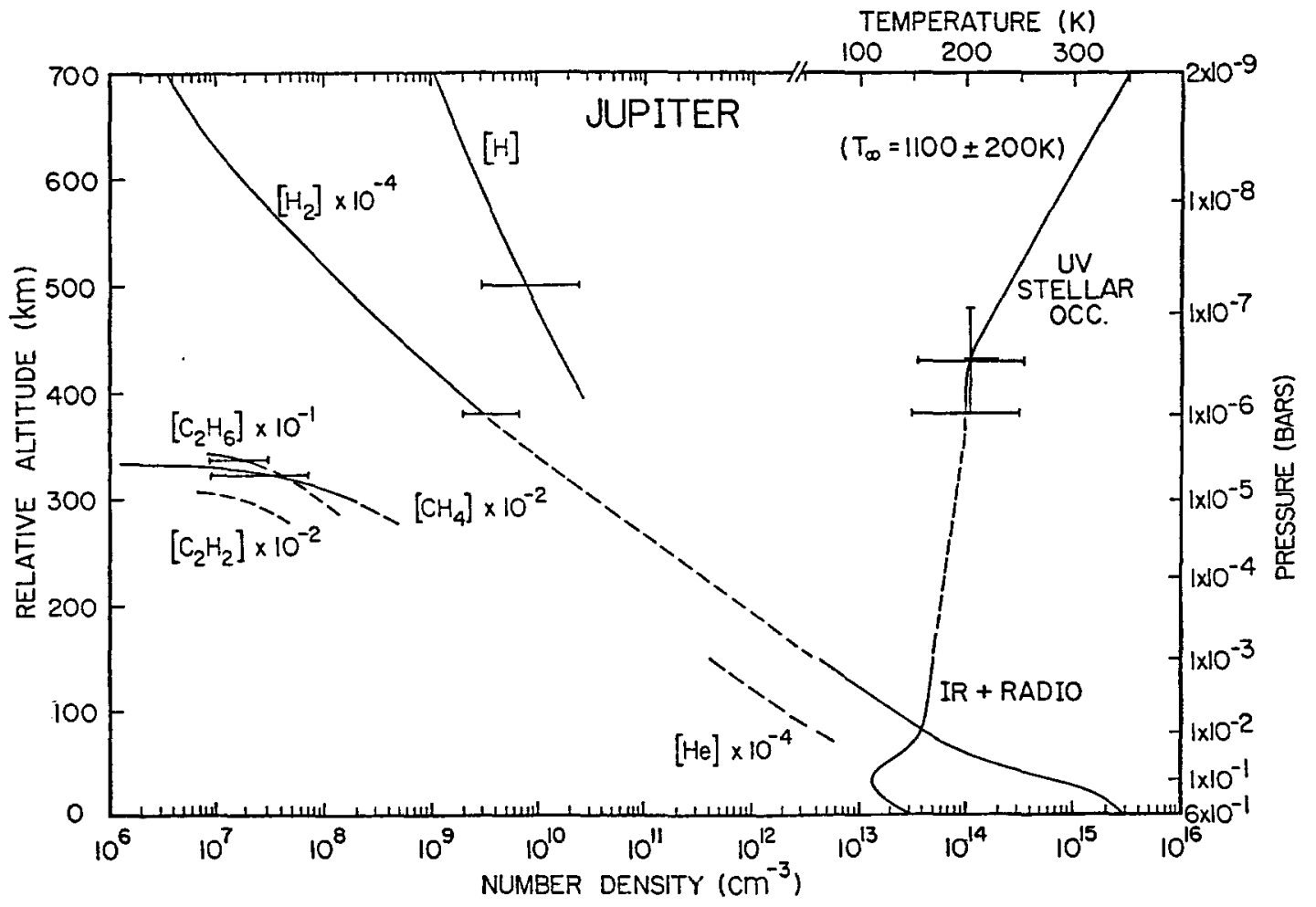

Fig. 4. Same as Figure 3, except for Jupiter /6/. 
Table 2. Eddy Diffusion Coefficient

\begin{tabular}{|c|c|c|c|c|}
\hline & \multirow[b]{2}{*}{$\begin{array}{l}\text { Eddy Diffusion } \\
\left(\mathrm{cm}^{2} \mathrm{~s}^{-1}\right)\end{array}$} & \multicolumn{3}{|c|}{ Homopause Characteristics } \\
\hline & & $\begin{array}{l}\text { Density } \\
\left(\mathrm{cm}^{-3}\right)\end{array}$ & $\begin{array}{l}\text { Altitude } \\
(\mathrm{km})\end{array}$ & $\begin{array}{l}\text { Pressure } \\
\text { (bar) }\end{array}$ \\
\hline Neptune & $10^{5}-10^{6}(?)$ & $(50-5) \times 10^{13}$ & $?$ & $10^{-5}-10^{-6}$ \\
\hline Uranus & $10^{4}-10^{5}$ & $(50-5) \times 10^{14}$ & $450-560$ & $2 \times 10^{-5}-10^{-5}$ \\
\hline Saturn & $\begin{array}{l}1.7(+4.3,-1.0) \times 10^{8} \\
8.0(+4.0,-4.0) \times 10^{7}\end{array}$ & $1.2 \times 10^{11}$ & 1100 & $4 \times 10^{-9}$ \\
\hline Jupiter & $1.4(+0.8,-0.7) \times 10^{6}$ & $1.4 \times 10^{13}$ & 440 & $10^{-6}$ \\
\hline Titan & $1.0(+2.0,-0.7) \times 10^{8}$ & $2.7 \times 10^{10}$ & $925 \pm 70$ & $6 \times 10^{-10}$ \\
\hline Earth & $(0.3-1) \times 10^{6}$ & $10^{13}$ & 100 & $3 \times 10^{-7}$ \\
\hline Venus & $10^{7}$ & $7.5 \times 10^{11}$ & $130-135$ & $2 \times 10^{-8}$ \\
\hline Mars & $(1.3-4.4) \times 10^{8}$ & $10^{10}$ & 135 & $2 \times 10^{-10}$ \\
\hline
\end{tabular}

$$
\begin{aligned}
\mathrm{C}_{2} \mathrm{H}_{2}+\mathrm{h} \nu & \rightarrow \mathrm{C}_{2} \mathrm{H}+\mathrm{H} \\
\mathrm{C}_{2} \mathrm{H}+\mathrm{C}_{2} \mathrm{H}_{2} & \rightarrow \mathrm{C}_{4} \mathrm{H}_{2}+\mathrm{H} \\
\mathrm{C}_{4} \mathrm{H}_{2}+\mathrm{h} \nu & \rightarrow 2 \mathrm{C}_{2} \mathrm{H} \\
\mathrm{C}_{2} \mathrm{H}+\mathrm{C}_{4} \mathrm{H}_{2} & \rightarrow \mathrm{C}_{6} \mathrm{H}_{2}+\mathrm{H} \\
\text { also, } \mathrm{C}_{4} \mathrm{H}_{2}+\mathrm{h} \nu & \rightarrow \mathrm{C}_{4} \mathrm{H}+\mathrm{H} \\
\text { followed by } \mathrm{C}_{4} \mathrm{H}+\mathrm{C}_{2} \mathrm{H}_{2} & \rightarrow \mathrm{C}_{6} \mathrm{H}_{2}+\mathrm{H}
\end{aligned}
$$

etc. 
The upper atmosphere of Uranus differs from that of Jupiter and Saturn in another respect. Here, the stable hydrocarbon products, acetylene and ethane, begin to condense at around the 5-10 mb level. This would result in the production of haze (aerosols) in the lower stratosphere. It is also expected that photochemistry would proceed beyond the formation of acetylene, so that polyacetylene would form, as shown in Table 3. Our photochemical calculations indicate diacetylene condensation occurs at around the $0.1 \mathrm{mb}$ level. Thus, formation of haze and aerosols in the upper atmosphere of Uranus is a definite possibility. The polyacetylenes, including diacetylene, absorb sunlight to approximately $3200 \AA$, unlike $\mathrm{C}_{2} \mathrm{H}_{2}$ and $\mathrm{C}_{2} \mathrm{H}_{6}$ which absorb to $\sim 1800 \AA$. Early indications from the Voyager Photopolarimeter and Imaging investigations $7,8 /$ are that aerosols are omnipresent in the atmosphere of Uranus. Virtually no information yet exists about Neptune's upper atmosphere. An upper limit to the measured Lyman-alpha emission there is $300 \mathrm{R} / 9 /$, implying perhaps a drastically reduced role of electroglow. Hydrocarbon aerosols are expected to form in the stratosphere of Neptune also. The Voyager encounter with Neptune in August, 1989 will complete the most exciting exploration of the outer planets undertaken so far.

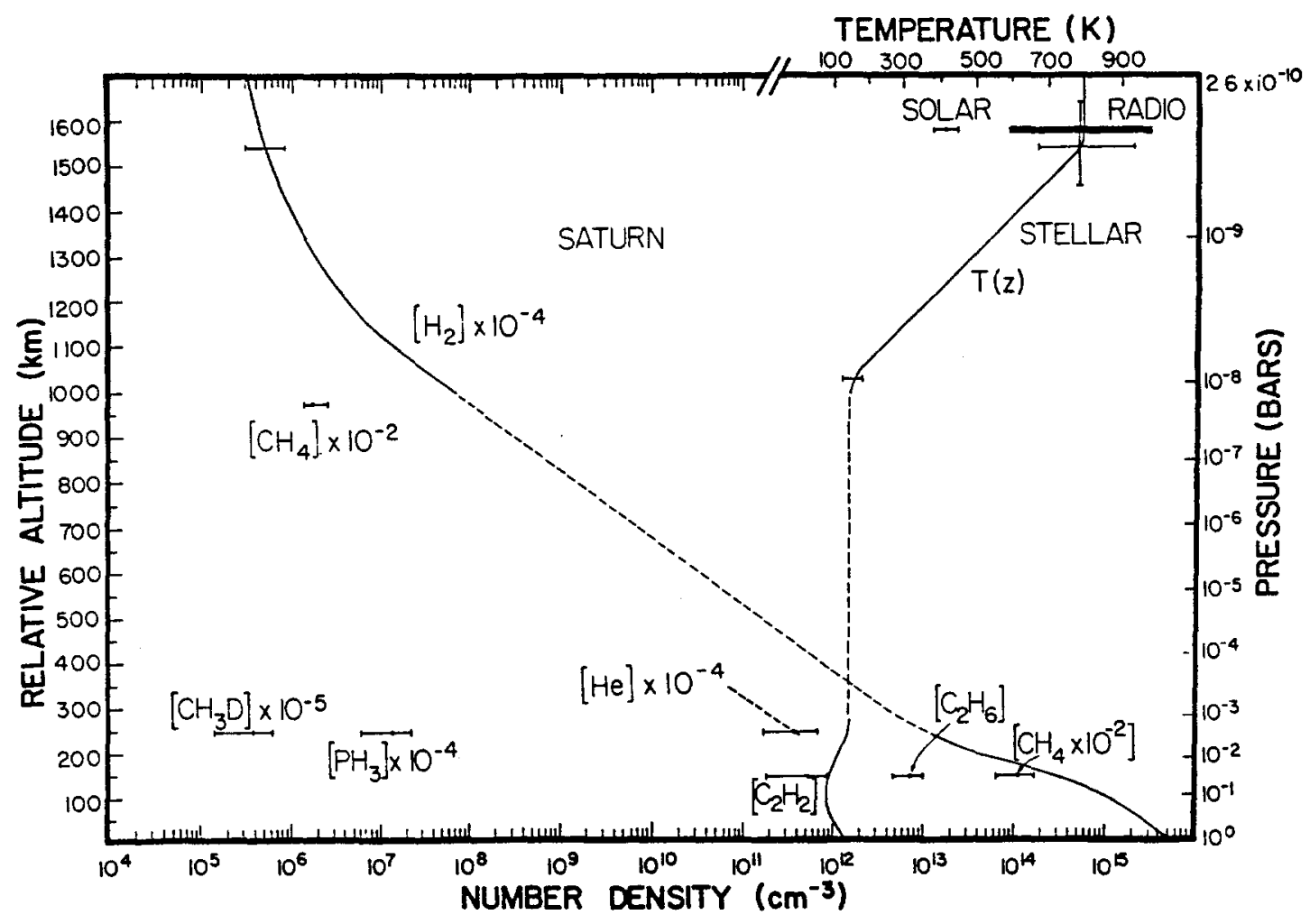

Fig. 5. Same as Figure 3, except for Saturn /1/. 


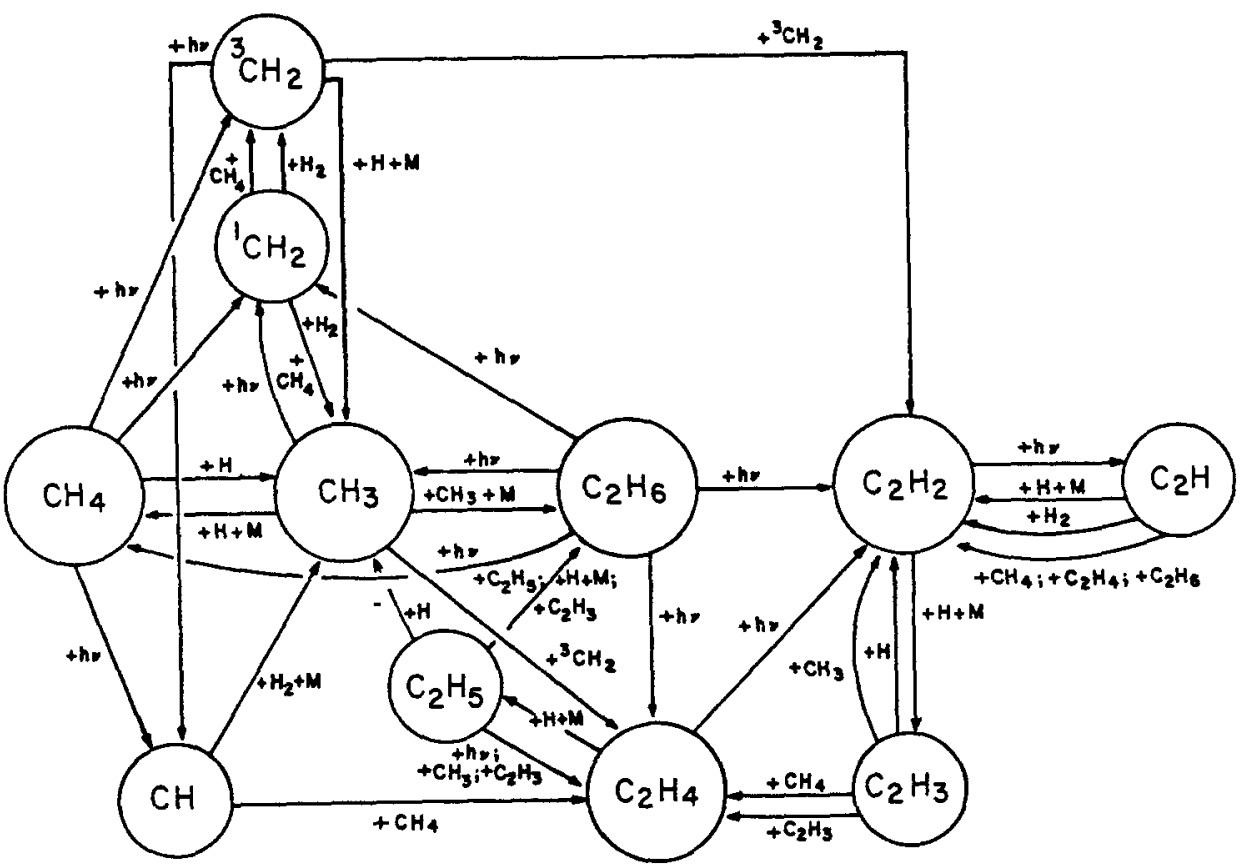

Fig. 6. Photochemistry of methane on the outer planets $/ 2 /$.

\section{ACKNOWLEDGMENTS}

This work was supported by a grant from the Planetary Atmospheres Program of NASA/Solar System Exploration Division. R. B. Kerr and J. T. Clarke provided helpful critiques of the manuscript.

\section{REFERENCES}

1. S.K. Atreya, J.H. Waite, T.M. Donahue, A.F. Nagy, and J.C. McConnell, Theory, measurements and models of the upper atmosphere and ionosphere of Saturn, in: Saturn, ed. E. Gehrels, Univ. Arizona Press, Tucson 1984, p. 239

2. S.K. Atreya, Atmospheres and lonospheres of the Outer Planets and their Satellites, Springer Verlag, New York and Heidelberg, 1986.

3. S.K. Atreya and P.N. Romani, Photochemistry and clouds of Jupiter, Saturn and Uranus, in: Planetary Meteorology, ed. G.E. Hunt, Cambridge Univ. Press, Cambridge 1985, p. 17

4. J.T. Clarke, S. Durrance, S.K. Atreya, A. Barnes, J. Belcher, M. Festou, C. Imhoff, J. Mihalou, W. Moos, J. Murthy, A. Pradhan, and T. Skinner, Continued Observations of the H Lyman-Alpha Emission from Uranus, J. Geophys. Res. 91, 8771 (1986)

5. A.L. Broadfoot, F. Herbert, J. Holberg, D. Hunten, B. Sandel, D. Shemansky, G. Smith, R. Yelle, S. Kumar, D. Strbel, H. Moos, S. Atreya, T. Donahue, J. Bertaux, J. Blamont, J. McConnell, A. Dessler, S. Linnick, and R. Springer, Ultraviolet Spectrometer Observations of Uranus, Science, 233, 74 (1986)

6. S.K. Atreya, T.M. Donahue, and M.C. Festou, Jupiter: Structure and composition of the upper atmosphere, Astrophys. J. 247, L43 (1981)

7. A.L. Lane, C. Hord, R. West, L. Esposito, K. Simmons, R. Nelson, B. Wallis, and B. Buratti, Photometry from Voyager 2: Initial results from the Uranian atmosphere, satellites and rings, Science 233, 65 (1986)

8. B.A. Smith, L. Soderblom, R. Beebe, D. Bliss, J. Boyce, A. Brahic, G. Briggs, R. Brown, S. Collins, A. Cook II, S. Croft, J. Cuzzi, G. Danielson, M. Davies, T. Dowling, D. Godfrey, C. Hansen, C. Harris, G. Hunt, A. Ingersoll, T. Johnson, R. Krauss, H. Masursky, D. Morrison, T. Owen, J. Plescia, J. Pollack, C. Porco, K. Rages, C. Saga, E. Shoemaker, L. Sromovsky, C. Stoker, R. Strom, V. Suomi, S. Synnotte, R. Terrile, P. Thomas, W. Thompson, and J. Veverka, Voyager 2 in the Uranus system: Imaging science results, Science 233, 43 (1986)

9. J. T. Clarke, private communication (1986) 